\title{
The Role of Body Mass Index, Insulin, and Adiponectin in the Relation Between Fat Distribution and Bone Mineral Density
}

\author{
M. Carola Zillikens • André G. Uitterlinden · Johannes P. T. M. van Leeuwen • \\ Anne L. Berends • Peter Henneman • Ko Willems van Dijk • Ben A. Oostra • \\ Cornelia M. van Duijn • Huibert A. P. Pols • Fernando Rivadeneira
}

Received: 12 May 2009/Accepted: 31 October 2009/Published online: 3 December 2009

(C) The Author(s) 2009. This article is published with open access at Springerlink.com

\begin{abstract}
Despite the positive association between body mass index (BMI) and bone mineral density (BMD) and content (BMC), the role of fat distribution in $\mathrm{BMD} / \mathrm{BMC}$ remains unclear. We examined relationships between $\mathrm{BMD} / \mathrm{BMC}$ and various measurements of fat distribution and studied the role of BMI, insulin, and adiponectin in these relations. Using a cross-sectional investigation of 2631 participants from the Erasmus Rucphen Family study, we studied associations between BMD (using dual-energy $\mathrm{X}$-ray absorptiometry (DXA]) at the hip, lumbar spine, total body (BMD and BMC), and fat distribution by the waist-to-hip ratio (WHR), waist-to-thigh ratio (WTR), and
\end{abstract}

M. C. Zillikens $(\bowtie) \cdot$ A. G. Uitterlinden ·

J. P. T. M. van Leeuwen - H. A. P. Pols - F. Rivadeneira Department of Internal Medicine, Erasmus Medical Center, Room D428, P.O. Box 2040, 3000CA Rotterdam,

The Netherlands

e-mail: m.c.zillikens@erasmusmc.nl

A. G. Uitterlinden - C. M. van Duijn · H. A. P. Pols ·

F. Rivadeneira

Department of Epidemiology, Erasmus Medical Center,

Rotterdam, The Netherlands

\author{
A. L. Berends \\ Department of Obstetrics and Gynecology, Erasmus Medical \\ Center, Rotterdam, The Netherlands \\ P. Henneman · K. W. van Dijk \\ Department of Human Genetics, Leiden University Medical \\ Center, Leiden, The Netherlands \\ K. W. van Dijk \\ Department of General Internal Medicine, Leiden University \\ Medical Center, Leiden, The Netherlands \\ B. A. Oostra \\ Department of Clinical Genetics, Erasmus Medical Center, \\ Rotterdam, The Netherlands
}

DXA-based trunk-to-leg fat ratio and android-to-gynoid fat ratio. Analyses were stratified by gender and median age (48.0 years in women and 49.2 years in men) and were performed with and without adjustment for BMI, fasting insulin, and adiponectin. Using linear regression (adjusting for age, height, smoking, and use of alcohol), most relationships between fat distribution and BMD and BMC were positive, except for WTR. After BMI adjustment, most correlations were negative except for trunk-to-leg fat ratio in both genders. No consistent influence of age or menopausal status was found. Insulin and adiponectin levels did not explain either positive or negative associations. In conclusion, positive associations between android fat distribution and BMD/BMC are explained by higher BMI but not by higher insulin and/or lower adiponectin levels. Inverse associations after adjustment for BMI suggest that android fat deposition as measured by the WHR, WTR, and DXA-based android-to-gynoid fat ratio is not beneficial and possibly even deleterious for bone.

Keywords Fat distribution - Bone mineral density · Body composition - Android-to-gynoid fat ratio . Waist-to-hip ratio $\cdot$ Insulin $\cdot$ Adiponectin

Osteoporosis and obesity are important global health problems with an increasing prevalence. A positive association between body weight or body mass index (BMI) and bone mineral density (BMD) has been clearly demonstrated, as well as increased fracture risk with low BMI [1-3]. Possible explanations for higher BMD in heavier people include the weight-bearing effect of both fat and lean mass, while lean mass is thought to influence bone through muscle-mediated effects of physical exercise. Furthermore, adipose tissue might influence BMD through the production of hormones 
and adipokines by adipocytes (e.g., estrogen, leptin, adiponectin, resistin, interleukins) or through an effect on the secretion of bone-active hormones from the pancreas (e.g., insulin, amylin, preptin) [3]. There is ongoing controversy about the relative importance of the fat and lean components of the body to BMD $[3,4]$. In postmenopausal women fat mass has been shown most consistently to be positively related to BMD, possibly mediated by higher estrogen levels. However, several discrepancies can be found in the literature, e.g., fat mass being important in young but not in old women and in old but not in young men [5].

The effect of fat distribution on BMD is far from clear. Adipose tissue is metabolically heterogeneous, with differences between visceral and subcutaneous fat, for example, in the production of adipokines and in the regulation of steroid hormone metabolism [6]. Android fat deposition (also called abdominal, central, visceral, or upper body fat distribution) leads to increased risk of chronic diseases like cardiovascular disease and type 2 diabetes [7], while larger hip and thigh circumferences in gynoid fat deposition are associated with decreased risk of metabolic disease, independently of waist circumference $[8,9]$. Circumference ratios, especially the waist-to-hip ratio (WHR) but also the waist-to-thigh ratio (WTR), have been consistently associated in epidemiological studies with metabolic and cardiovascular disease [7, 8]. Several physiological factors that are associated with fat distribution are also associated with BMD. These include age, gender, heredity, parity, menopausal status, physical activity, smoking and alcohol consumption, and hormones such as sex steroids, glucocorticoids, growth hormones, insulin, leptin, and adiponectin $[3,10,11]$. Studies on the relationship between body fat distribution and BMD have yielded conflicting results. In late postmenopausal women in the Study of Osteoporotic Fractures, WHR was found to have no important relationship to BMD compared to weight [12]. Heiss et al. found that upper-body obesity was associated with increased BMD [13], possibly due to higher levels of insulin, lower levels of sex hormone binding globulin (SHBG), and higher free sex-steroid levels. Other studies also reported positive relations between android fat distribution and BMD [5, 14-18]. In contrast, two small studies found negative associations between android obesity and BMD or bone mineral content (BMC) [19, 20], and this was also seen in prepubertal children [21] and HIV-infected patients [22]. Most studies included a small number of subjects and/or were not population based, and different techniques were used for measurement of BMD or BMC (dual-energy X-ray absorptiometry [DXA] or peripheral CT) and fat distribution (anthropometry, DXA, CT, or MRI). Also, the effect of adiposity on the relationship between fat distribution and BMD was not always considered. Since, in general, increased obesity is associated with increased abdominal fatness, BMI might be a confounder in the relation between android obesity and BMD. Despite suggestions that android fat deposition is beneficial for bone through higher insulin and/or lower adiponectin levels [11, 13], their role in the relation between fat distribution and bone has not been fully explored.

The aim of the present study was to examine the relationship between various types of fat distribution assessment and BMD and BMC in a large number of Caucasian subjects from a genetically isolated population in The Netherlands and to explore potential gender and age differences in this relationship, as well as the effect of BMI and plasma insulin and adiponectin.

\section{Materials and Methods}

\section{Study Population}

This study was carried out within the Erasmus Rucphen Family (ERF) study, a family-based cohort study that is embedded in the Genetic Research in Isolated Populations program in the southwestern Netherlands. The aim of this program was to identify genetic risk factors in the development of complex disorders [23-26].

For the ERF study, 22 families that had at least 5 children baptized in the community church between 1850 and 1900 were identified with the help of genealogical records. All living descendants of these couples and their spouses were invited to take part in the study. Data collection started in June 2002 and was completed in February 2005. In this study, we focused on the 2631 participants for whom complete phenotypic and genealogical information was available. The Medical Ethics Committee of Erasmus Medical Center Rotterdam approved the study. Written informed consent was obtained from all participants.

\section{Data Collection}

At the research center, located within the community, extensive clinical examinations were performed, including collection of fasting blood samples, anthropometric measurements, DXA, and personal interviews. A research physician obtained information on medical history, medication use, smoking, and alcohol use in a personal interview.

\section{Anthropometric Measurements}

Height and weight were measured with the participant dressed in light underclothing. BMI was calculated from these data (weight $[\mathrm{kg}] / \mathrm{height}^{2}\left[\mathrm{~m}^{2}\right]$ ). Circumferences of the waist, hip, and thigh were measured using a tape measure with the participant in a standing position without 
outer garments. Waist circumference was measured halfway between the rib cage and the pelvic bone. Hip circumference was measured at the maximal circumference of the hips. Thigh circumference was measured midway between the upper border of the patella and the inguinal fold on the right leg. The WHR and WTR were calculated from these measurements.

\section{Dual-Energy X-Ray Absorptiometry Measurements}

DXA scans were performed using a Prodigy total-body fanbeam densitometer and analyzed with the enCORE 2005 software v.9.3 (DPX; Lunar Corp., Madison, WI, USA) as described previously [26]. BMD was measured at the femoral neck (mean value of left and right) and lumbar spine (L1-L4), while for the total body both BMD and BMC were used, as both estimates have been used in other studies. Total-body scans were autoanalyzed by the software, which employs an algorithm that divides body measurements into areas corresponding to head, trunk, arms, and legs.

Total-body fat mass (g), lean mass (g), and regional fat mass were obtained from total-body scans. The trunk region was limited by vertical borders lateral to the ribs and a lower border by the iliac crest and an upper horizontal border below the chin (neck cut), above which the head was defined. The arm region was limited by cuts that cross the arm sockets, as close to the body as possible, and separate the arms and hands from the body. The leg region is limited above by the oblique lines passing through the hip joint and cuts that separate the hands and forearms from the legs and a center leg cut which separates the right and left leg. Additional "android" and "gynoid" regions were defined using the software provided by the manufacturer. The "android region" has a lower boundary at the pelvis cut and the upper boundary above the pelvis cut by $20 \%$ of the distance between the pelvis and the neck cuts. The lateral boundaries are the arm cuts. The "gynoid region" has an upper boundary between the upper part of the greater trochanters and a lower boundary defined at a distance equal to twice the height of the android region. The lateral boundaries are the outer leg cuts. The android and gynoid fat mass and android-to-gynoid fat ratio were calculated from these measurements. A schematic representation of the trunk, leg, android, and gynoid region is shown in Fig. 1b. All analyses were verified by a trained technician who performed adjustments when necessary. Total-body DXA scans from 12 extremely obese subjects (BMI, $43.5-61.8 \mathrm{~kg} / \mathrm{m}^{2}$ ) were excluded from the analysis due to inadequate regions of interest which did not cover all body parts. Daily quality assurance tests were performed with a calibration block supplied by the manufacturer. Repeated measurements on the calibration block had coefficients of variation $<0.5 \%$. In addition, a calibration
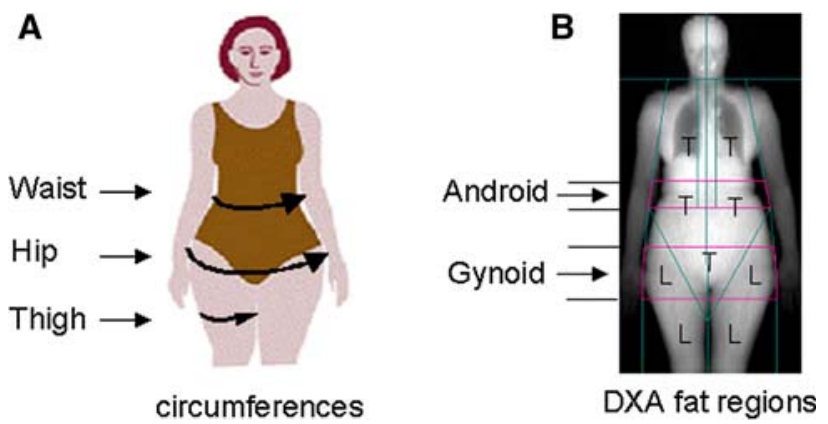

Fig. 1 a Sites of the circumference measurements. b Regions of trunk fat $(T)$, leg fat $(L)$, "android" fat, and "gynoid" fat assessed by DXA

aluminum phantom was measured weekly, with coefficients of variation $<0.5 \%$. The precision of the DXA methods for BMD, BMC, and body composition is excellent. Interobserver $\mathrm{CV}$ has been reported to be $<3.5 \%$ for BMD, BMC, and android and gynoid fat [27].

In Fig. 1 the sites of circumference measurements and fat regions by DXA are shown.

\section{Laboratory Examinations}

Fasting plasma insulin was analyzed with the INS-Irma kit of Biosource (cat. no. KIP1254) and total plasma adiponectin was analyzed with the human adiponectin RIA kit (cat. no. HADP-61HK) of Linco Research (St. Charles, MO, USA). All measurements were performed according to the manufacturer's protocol. The coefficients of variation were $<5 \%$ for plasma insulin and $<8 \%$ for adiponectin. For logistic reasons only 2104 plasma samples were analyzed.

\section{Statistical Analysis}

The associations between fat distribution parameters and BMI, BMD/BMC, and plasma levels of insulin and adiponectin were studied as partial correlations with correction for age. Multivariate linear regression analyses were performed to evaluate the strength of the relationship between body fat distribution and BMD and BMC. In the regression models, BMD and BMC, which were normally distributed, were used as dependent variables. Fat distribution parameters with a normal or near-normal distribution were used untransformed as independent variables, while age, height, and lifestyle factors (smoking and alcohol history) were also included because of their known association with bone and body composition. Smoking of cigarettes was categorized as never, past, or current. Alcohol use was categorized as no drinking, 1-21 units a week, or $>21$ units a week. Additional adjustment for BMI was applied to evaluate its role as a possible confounder. To study the effect of plasma insulin and adiponectin, 
regression analyses were performed with and without adjustment for these hormones. The results of multivariate regressions are expressed as standardized regression coefficients. A $P$-value $<0.05$ was considered significant. To examine the effect of age, the study population was divided by median age ( 48.0 years for women and 49.2 years for men), in order to have equal numbers of subjects per group. For women, analyses were repeated stratified by menopausal status (premenopausal vs. postmenopausal subjects). All statistical analyses were done using the statistical package SPSS for Windows, version 15.0.

\section{Results}

Table 1 reports general and body composition characteristics, BMD at the femoral neck and lumbar spine, and BMD and BMC at the total body for the study population. Mean age was 47.7 years for women and 48.6 years for men. About $46 \%$ of women were postmenopausal. As expected,

Table 1 General and body composition characteristics of the study population

\begin{tabular}{lll}
\hline & Females & Males \\
\hline Number & 1467 & 1164 \\
Age (years) & $47.7 \pm 14.2$ & $48.6 \pm 14.0$ \\
Range & $16.7-86.1$ & $17.6-84.7$ \\
Postmenopausal & $673(45.9 \%)$ & \\
Height $(\mathrm{m})$ & $1.62 \pm 0.06$ & $1.75 \pm 0.07$ \\
Weight $(\mathrm{kg})$ & $69.2 \pm 12.8$ & $83.0 \pm 13.3$ \\
Body mass index $\left(\mathrm{kg} / \mathrm{m}^{2}\right)$ & $26.4 \pm 4.7$ & $27.1 \pm 3.9$ \\
Waist-to-hip ratio & $0.80 \pm 0.08$ & $0.94 \pm 0.08$ \\
Waist-to-thigh ratio & $1.62 \pm 0.20$ & $1.85 \pm 0.20$ \\
Android-to-gynoid fat ratio & $0.45 \pm 0.15$ & $0.71 \pm 0.20$ \\
Trunk-to-leg fat ratio & $1.52 \pm 0.46$ & $2.42 \pm 0.64$ \\
Femoral neck BMD $\left(\mathrm{g} / \mathrm{cm}^{2}\right)$ & $0.91 \pm 0.13$ & $0.97 \pm 0.14$ \\
L1-L4 BMD $\left(\mathrm{g} / \mathrm{cm}^{2}\right)$ & $1.12 \pm 0.16$ & $1.18 \pm 1.94$ \\
Total body BMD $\left(\mathrm{g} / \mathrm{cm}^{2}\right)$ & $1.10 \pm 0.95$ & $1.21 \pm 0.10$ \\
Total body BMC $(\mathrm{kg})$ & $2.32 \pm 0.67$ & $3.04 \pm 0.44$ \\
Insulin $(\mu \mathrm{U} / \mathrm{ml})(n=2104)$ & $12.8 \pm 6.3$ & $13.7 \pm 8.8$ \\
Adiponectin $(\mathrm{mg} / \mathrm{L})(n=2104)$ & $12.3 \pm 5.8$ & $8.0 \pm 4.1$ \\
Smoking & & \\
Never & & \\
Past & $620(28.6)$ & $398(34.2)$ \\
Current & $394(26.9)$ & $375(32.2)$ \\
Alcohol & $653(44.5)$ & $391(33.6)$ \\
$<1$ unit per week & & \\
1-21 units per week & $681(46.4)$ & $221(19.0)$ \\
$>21$ units per week & $834(71.6)$ \\
\hline
\end{tabular}

Note. Values are presented as number (percentage) or mean \pm standard deviation men were taller and had higher values for all fat distribution parameters, consistent with men having a more android (apple-shaped) and women a more gynoid (pear-shaped) fat distribution. Men also had higher BMD values. Fasting plasma levels and adiponectin levels were lower in men.

Table 2 reports partial correlations corrected for age among BMI, the four fat distribution parameters, BMD/ $\mathrm{BMC}$, and fasting plasma levels of insulin and adiponectin. Regarding the relation between BMI and the fat distribution parameters, in women, the highest correlation was found between BMI and android-to-gynoid fat ratio $(r=0.59)$, followed by WHR $(r=0.44)$, while in men the highest correlation with BMI was found for WHR $(r=0.58)$, followed by android-to-gynoid fat ratio $(r=0.46)$. Both in women and in men, trunk-to-leg fat ratio had the lowest correlations with BMI ( $r=0.26$ and $r=0.20$ for women and men, respectively). Correlations between the fat distribution parameters themselves ranged between 0.43 and 0.84 , with the highest correlation between WHR and WTR and between the android-to-gynoid fat ratio and the trunk-toleg fat ratio.

Fat distribution parameters were significantly correlated with BMD and BMC at several sites and correlations were mostly positive (highest $r$ of 0.19 in females and 0.12 in males). Negative correlations were found for waist-to-thigh ratio (in females with total-body BMC and in males at all sites).

Fasting levels of plasma insulin were positively correlated with BMI, fat distribution parameters, and total-body BMD in both genders and, additionally, with femoral neck BMD in males only. Fasting plasma levels of adiponectin showed negative correlations with BMI and fat distribution. There were also inverse correlations between adiponectin and all BMD/BMC measurements.

Table 3 reports the same relationship as in Table 2 between the four parameters of fat distribution and BMD and/or BMC at three sites, expressed as standardized $\beta$ coefficients after standard adjustment for age, height, smoking, and alcohol intake (model 1) and after additional adjustment for BMI and plasma insulin and adiponectin. Adjustment for plasma insulin (model 2) or plasma adiponectin (model 3) resulted in only minor changes in $\beta$ coefficients and $P$-values. However, after adjustment for BMI (model 4) most relations changed and were negative. Negative relations were strongest for the waist-to-thigh ratio and waist-to-hip ratio. For the android-to-gynoid fat ratio negative relations were significant only with totalbody BMD and BMC in both genders. For the trunk-to-leg fat ratio there was a small persisting positive relation with lumbar spine BMD after adjustment for BMI. Additional adjustment for either insulin (model 5) or adiponectin (model 6) with BMI in the models resulted again in only minor changes in $\beta$ coefficients. In general, they decreased 


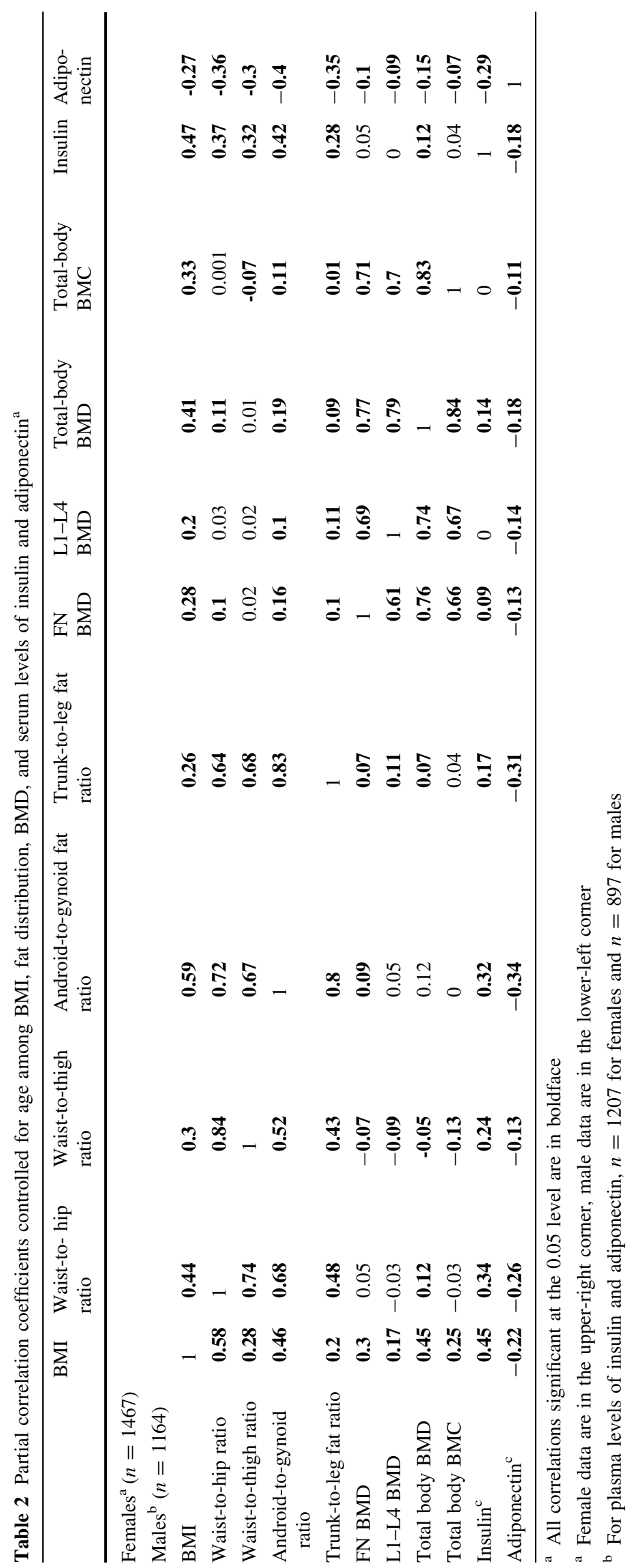




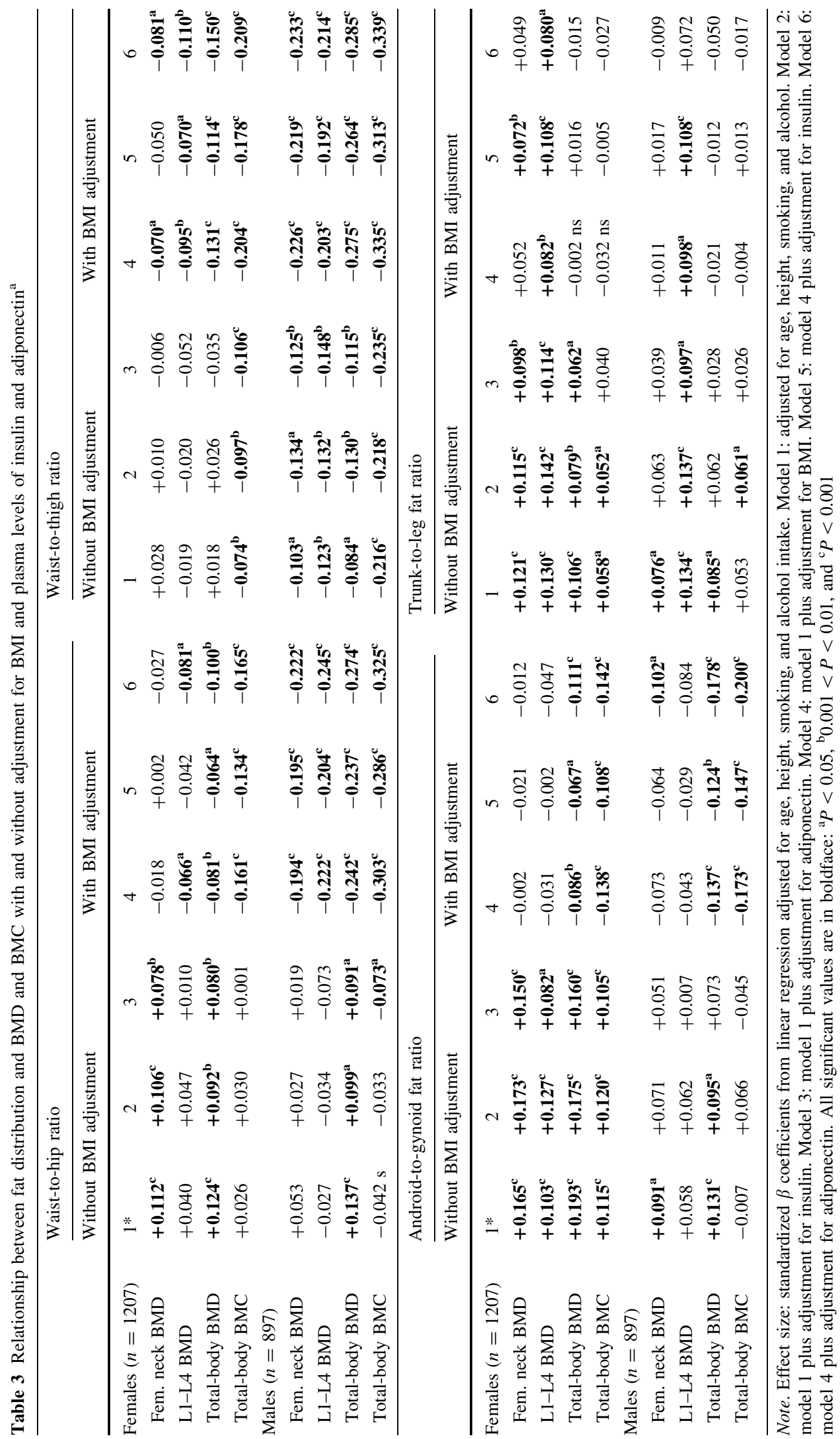


Table 4 Relationship between fat distribution and BMD and BMC in males and females stratified by median age

\begin{tabular}{|c|c|c|c|c|c|c|c|c|}
\hline & \multicolumn{2}{|c|}{ Waist-to-hip ratio } & \multicolumn{2}{|c|}{ Waist-to-thigh ratio } & \multicolumn{2}{|c|}{ Android-to-gynoid fat } & \multicolumn{2}{|l|}{ Trunk-to-leg fat } \\
\hline & $\leq$ Median age & $>$ Median age & $\leq$ Median age & $>$ Median age & $\leq$ Median age & $>$ Median age & $\leq$ Median age & $>$ Median age \\
\hline \multicolumn{9}{|c|}{ A: Without adjustment for BMI } \\
\hline Females, $n$ & 734 & 733 & 734 & 733 & 734 & 733 & 734 & 733 \\
\hline Fem. neck BMD & $+0.146^{c}$ & $+0.101^{b}$ & +0.054 & +0.024 & $+0.138^{c}$ & $+0.155^{\mathrm{c}}$ & $+0.127^{\mathrm{c}}$ & $+0.115^{\mathrm{c}}$ \\
\hline L1-L4 BMD & +0.024 & +0.049 & -0.046 & +0.007 & +0.059 & $+0.103^{b}$ & $+0.128^{c}$ & $+0.131^{c}$ \\
\hline Total BMD & $+0.176^{\mathrm{c}}$ & $+0.106^{b}$ & +0.042 & +0.036 & $+0.203^{c}$ & $+0.163^{c}$ & $+0.143^{c}$ & $+0.091^{b}$ \\
\hline Total BMC & $+0.082^{b}$ & -0.003 & -0.032 & $-0.070^{a}$ & $+0.145^{c}$ & +0.058 & $+0.112^{c}$ & +0.025 \\
\hline Males, $n$ & 582 & 582 & 582 & 582 & 582 & 582 & 582 & 582 \\
\hline Fem. neck BMD & +0.077 & +0.078 & $-0.091^{\mathrm{a}}$ & -0.063 & +0.099 & +0.070 & +0.068 & +0.087 \\
\hline L1-L4 BMD & -0.031 & -0.010 & $-0.164^{\mathrm{c}}$ & -0.066 & -0.025 & +0.070 & +0.072 & $+0.154^{\mathrm{c}}$ \\
\hline Total BMD & $+0.149^{b}$ & $+0.122^{b}$ & -0.079 & -0.035 & +0.115 & +0.094 & +0.061 & +0.072 \\
\hline Total BMC & -0.019 & -0.064 & $-0.171^{c}$ & $-0.179^{c}$ & -0.019 & -0.038 & +0.051 & +0.036 \\
\hline \multicolumn{9}{|c|}{ B: With adjustment for BMI } \\
\hline \multicolumn{9}{|l|}{ Females } \\
\hline Fem. neck BMD & +0.045 & -0.048 & -0.010 & $-0.092^{\mathrm{a}}$ & -0.031 & -0.008 & +0.052 & +0.055 \\
\hline L1-L4 BMD & $-0,063$ & -0.066 & $-0.095^{\mathrm{a}}$ & $-0.079^{a}$ & -0.082 & -0.019 & $+0.081^{\mathrm{a}}$ & $+0.090^{\mathrm{a}}$ \\
\hline Total BMD & $-0,016$ & $-\mathbf{0 . 1 0 3}^{\mathbf{b}}$ & -0.070 & $-0.119^{b}$ & $-0.112^{\mathrm{a}}$ & $-0.076^{\mathrm{a}}$ & +0.004 & +0.006 \\
\hline Total BMC & $-0.099^{b}$ & $-0.180^{c}$ & $-\mathbf{0 . 1 3 3}^{\mathrm{c}}$ & $-\mathbf{0 . 2 0 3}^{\mathrm{c}}$ & $-0.146^{c}$ & $-0.157^{c}$ & -0.009 & -0.042 \\
\hline \multicolumn{9}{|l|}{ Males } \\
\hline Fem. neck BMD & $-0.157^{b}$ & $-0.198^{c}$ & $-0.177^{\mathrm{c}}$ & $-0.205^{\mathrm{c}}$ & -0.061 & $-0.098^{a}$ & +0.020 & +0.012 \\
\hline L1-L4 BMD & $-0.257^{\mathrm{c}}$ & $-0.179^{c}$ & $-0.203^{c}$ & $-0.155^{\mathrm{c}}$ & $-0.101^{\mathrm{a}}$ & -0.027 & +0.061 & $+0.114^{b}$ \\
\hline Total BMD & $-0.231^{\mathrm{c}}$ & $-0.233^{c}$ & $-0.217^{\mathrm{c}}$ & $-0.219^{c}$ & $-0.166^{\mathrm{c}}$ & $-0.129^{c}$ & -0.019 & -0.029 \\
\hline Total BMC & $-0.295^{\mathrm{c}}$ & $-0.287^{c}$ & $-0.260^{c}$ & $-0.280^{c}$ & $-0.210^{c}$ & $-0.156^{c}$ & +0.004 & -0.009 \\
\hline
\end{tabular}

Note. Effect size: standardized $\beta$ coefficients from linear regression adjusted for age, height, smoking, and alcohol intake. Median age: 48.0 years for women and 49.2 years for men. All significant values are in boldface: ${ }^{\mathrm{a}} P<0.05 ;{ }^{\mathrm{b}} 0.001<P<0.01 ;{ }^{\mathrm{c}} P<0.001$

after adjustment for insulin and increased after adjustment for adiponectin. The strongest negative relations were seen for the waist-to-thigh ratio with total-body BMC in males. The $\beta$ coefficients ( $P$-values $)$ were $-0.335(P=1.5 \times$ $\left.10^{-21}\right)$ after BMI adjustment, $-0.313\left(P=2.7 \times 10^{-19}\right)$ after BMI and insulin adjustment, and $-0.339(P=3.5 \times$ $10^{-22}$ ) after BMI and adiponectin adjustment.

Overall, across measurements, $\beta$ coefficients were more negative in males than in females. In both genders, $\beta$ coefficients for the relation of fat distribution parameters with total-body BMC were lower than those with totalbody BMD. After adjustment for BMI, the associations between various fat distribution measures and total-body BMD and BMC became more similar.

In Table 4 the relationships between fat distribution and BMD are presented stratified by median age in both genders. There were no consistent differences between the age groups, although relations of fat distribution parameters with total-body BMC appeared to be more positive without adjustment for BMI in younger compared to older women and more negative after BMI adjustment in older women.
Outcomes were essentially unchanged when we stratified women by postmenopausal status instead of median age and also when we adjusted our analyses in both genders for body weight instead of BMI (data not shown).

The total variation of BMD explained by fat distribution parameters independent of age, height, BMI, smoking, and alcohol intake was smaller than the variation explained by BMI independent of age, height, smoking, and alcohol intake. Variation explained by BMI for femoral neck BMD, lumbar spine BMD and total body BMD and BMC was, respectively, $5.7 \%, 2.9 \%, 13.2 \%$, and $9.0 \%$ in women and $7.8 \%, 2.4 \%, 19.0 \%$, and $5.0 \%$ in men.

Variation explained by the four fat distribution parameters independent of BMI at these sites was as follows: for waist-to-hip ratio, $0.0 \%, 0.2 \%, 0.3 \%$, and $1.3 \%$ in women and $1.6 \%, 2.1 \%, 2.6 \%$, and $4.0 \%$ in men; for waist-to-thigh ratio, $0.0 \%, 0.6 \%, 0.9 \%$, and $2.3 \%$ in women and $1.8 \%$, $1.8 \%, 3.0 \%$, and $4.9 \%$ in men; for android-to-gynoid fat ratio, $0.0 \%, 0.1 \%, 0.4 \%$, and $1.3 \%$ in women and $0.5 \%$, $0.1 \%, 1.2 \%$, and $1.8 \%$ in men; and for trunk-to-leg fat ratio, $0.2 \%, 0.5 \%, 0.0 \%$, and $0.0 \%$ in women and $0.0 \%$, $0.7 \%, 0.0 \%$, and $0.0 \%$ in men, respectively. 


\section{Discussion}

In this study we show that positive associations between android fat distribution and BMD are largely explained by higher BMI. Once the effect of BMI is taken into account, android fat distribution has no or negative relationships with BMD. We also show that these relationships depend on the type of fat distribution parameter used and the site of BMD/BMC measurement. We also demonstrate that relations are independent of plasma levels of insulin and adiponectin. These observations may explain inconsistent findings of positive, negative, or no associations between fat distribution and BMD in previous studies [5, 13-18], since adjustment for BMI was performed only in some studies. In addition, such studies have focused on measurement on BMD at different sites and used diverse parameters of fat distribution. Moreover, our findings challenge the view that android fat deposition is beneficial for bone through higher insulin and/or lower adiponectin levels $[11,13]$.

Most of the positive associations we found between BMD and fat distribution are indeed explained by increased BMI. After removing the effect of BMI by adjusting for it in the multiple regression models, no more positive associations were found except for small but significant positive relationships between trunk-to-leg fat ratio and lumbar spine BMD. In contrast, several associations became significantly negative, with the lowest $\beta$ regression coefficients appearing for the circumference ratios WHR and WTR, followed by the android-to-gynoid fat ratio, with no negative associations for the trunk-to-leg fat ratio. Thus, despite high correlations between the different parameters of fat distribution, there were clear differences in their relation with BMD but also with BMI. This shows that they do not measure the same aspect of fat distribution. Circumference measurements are related not only to the amount of adipose tissue but also to the size of internal organs (waist circumference) and the size of bone and muscle (hip and thigh), the latter especially in men $[8,9]$. This may influence the relation with BMD irrespective of fat distribution. The new DXA-based measurement of fat in the abdominal region has a high correlation $(r>0.87)$ with abdominal fat by CT scanning [28] and is theoretically more closely related to visceral fat than total trunk fat mass, which also contains subcutaneous adipose tissue on the thorax, back, and breasts. Another advantage of the android-to-gynoid fat ratio over the trunk-to-leg fat ratio is that, in the latter assessment, gluteal and abdominal fat cannot be perfectly separated [29]. However, neither anthropometry nor DXA can distinguish between visceral and subcutaneous fat in the android region, although waist circumference as well as trunk fat and abdominal fat in a subregion by DXA shows a high correlation with visceral fat measured by $\mathrm{CT}$ or MRI [28, 30-34].

The only association that remained significantly positive in our study after BMI adjustment was between trunk-to-leg fat ratio and lumbar spine BMD, consistent with findings by Douchi et al. [15]. It is unclear whether this is caused by the fact that the trunk-to-leg fat ratio is not a good estimate of fat distribution, or due to an artifact in the DXA measurement, as was observed after simulating changes in trunk fat with lard packets [35]. On the other hand, we cannot exclude that the observed relationship is real and that (subcutaneous) fat in the trunk, as opposed to the legs, produces factors that are beneficial to bone.

There were small gender differences in our study, with males showing less positive (before BMI adjustment) and more negative (after BMI adjustment) relationships between fat distribution and BMD or BMC than women. This might be caused by a potentially stronger relation in males between hip and thigh circumference and lowerbody muscularity $[8,9]$, since these differences were most marked for the waist-to-hip and waist-to-thigh ratios. We found differences by site of BMD/BMC measurement. Regression coefficients were in general lower for totalbody BMC than for hip, lumbar spine, and total-body BMD. We observed differences in $\beta$ coefficients between various fat distribution measures and total-body BMD and BMC, all of which decreased after adjustment for BMI. To our surprise we found no consistent age differences in the relationship between fat distribution and BMD/BMC. Considering the strong effect of menopause and age on fat distribution and BMD [36, 37], the similarity in their relationships between younger and older women is remarkable.

There are several reasons why it is important to study the relationships between fat distribution and BMD and to try to explain previous controversial findings. It is important for fracture risk prediction, patient handling, and understanding of biological mechanisms. Our study shows that measures of fat distribution explain more of the variation in BMD and BMC in men than in women but the effect is relatively small compared to that of weight and BMI. In that respect our data are in agreement with those from the Study of Osteoporotic Fractures in older women [12] but now extend these findings to males and younger subjects. For patient care, it is important to know that android obesity does not appear to be beneficial for bone, as was suggested by most previous studies. Instead, our data show that, especially for males, gynoid fat distribution is better than android, possibly in part because it is a marker of greater physical activity, with greater muscle mass on hips and thighs. Thus, our data comply with and underscore the importance of the advice for regular 
physical exercise, which can potentially decrease android obesity and also prevents muscle wasting with aging and increases mechanical loading on the skeleton. Mediators other than physical activity might be considered as possible mechanistic explanations for our findings such as glucocorticoids, growth and sex hormones, leptin, and inflammatory adipokines. Our data show that it is unlikely that insulin and adiponectin mediate the association. Finally, technical limitations of the DXA technique should be considered in the interpretation of these findings since the BMD measurement is influenced by the fat-to-lean ratio of soft tissues [38].

Given the cross-sectional nature of our study, it is not possible to make causal inferences from associations or to study the relationship of fat distribution with fractures. We acknowledge that multiple testing may influence some of the significant findings in our study. However, even after applying a Bonferroni correction, which might be too stringent considering the high correlation between the fat distribution traits, most correlations would remain significant. Considering the consistency of the results across genders, we do not expect multiple testing to play a substantial role in the interpretation of our findings. We cannot exclude that our results could be influenced by the fact that our participants belong to a genetically isolated population. Yet it is unlikely that inbred characteristics influence the correlations between phenotypic measurements. Strengths of our study include the large population, which is not selected on disease and which includes both genders, with a wide age range, and the use of multiple bone sites and fat distribution parameters, including a new android-to-gynoid fat ratio by DXA and the availability of plasma levels of insulin and adiponectin.

We conclude that positive associations between android fat distribution and BMD are explained by higher BMI and not by higher insulin levels and/or lower adiponectin levels. Negative associations after adjustment for BMI suggest that android fat deposition as measured by the WHR, WTR, and android-to-gynoid fat ratio is not beneficial and possibly even deleterious for bone. The clinical relevance of these associations needs to be shown by studying a relation with fractures.

Acknowledgments This work was supported by a grant from the Center for Medical Systems Biology (CMSB) within the framework of the Netherlands Genomics Initiative (NGI)/Netherlands Organization for Scientific Research (NWO) and by the NCHA, the Netherlands consortium for Healthy Aging. We thank the participants in the Erasmus Rucphen Family study, the local health-care centers, and the municipalities for making this study possible.

Open Access This article is distributed under the terms of the Creative Commons Attribution Noncommercial License which permits any noncommercial use, distribution, and reproduction in any medium, provided the original author(s) and source are credited.

\section{References}

1. Reid IR (2002) Relationships among body mass, its components, and bone. Bone 31:547-555

2. De Laet C, Kanis JA, Oden A, Johanson H, Johnell O, Delmas P, Eisman JA, Kroger H, Fujiwara S, Garnero P, McCloskey EV, Mellstrom D, Melton LJ III, Meunier PJ, Pols HA, Reeve J, Silman A, Tenenhouse A (2005) Body mass index as a predictor of fracture risk: a meta-analysis. Osteoporos Int 16:1330-1338

3. Reid IR (2008) Relationships between fat and bone. Osteoporos Int 19:595-606

4. Chen Z, Lohman TG, Stini WA, Ritenbaugh C, Aickin M (1997) Fat or lean tissue mass: which one is the major determinant of bone mineral mass in healthy postmenopausal women? J Bone Miner Res 12:144-151

5. Makovey J, Naganathan V, Sambrook P (2005) Gender differences in relationships between body composition components, their distribution and bone mineral density: a cross-sectional opposite sex twin study. Osteoporos Int 16:1495-1505

6. Kershaw EE, Flier JS (2004) Adipose tissue as an endocrine organ. J Clin Endocrinol Metab 89:2548-2556

7. Emery EM, Schmid TL, Kahn HS, Filozof PP (1993) A review of the association between abdominal fat distribution, health outcome measures, and modifiable risk factors. Am J Health Promot 7:342-353

8. Snijder MB, Dekker JM, Visser M, Yudkin JS, Stehouwer CD, Bouter LM, Heine RJ, Nijpels G, Seidell JC (2003) Larger thigh and hip circumferences are associated with better glucose tolerance: the Hoorn study. Obes Res 11:104-111

9. Snijder MB, Visser M, Dekker JM, Goodpaster BH, Harris TB, Kritchevsky SB, De Rekeneire N, Kanaya AM, Newman AB, Tylavsky FA, Seidell JC (2005) Low subcutaneous thigh fat is a risk factor for unfavourable glucose and lipid levels, independently of high abdominal fat. The Health ABC Study. Diabetologia 48:301-308

10. Barrett-Connor E, Kritz-Silverstein D (1996) Does hyperinsulinemia preserve bone? Diabetes Care 19:1388-1392

11. Lenchik L, Register TC, Hsu FC, Lohman K, Nicklas BJ, Freedman BI, Langefeld CD, Carr JJ, Bowden DW (2003) Adiponectin as a novel determinant of bone mineral density and visceral fat. Bone 33:646-651

12. Glauber HS, Vollmer WM, Nevitt MC, Ensrud KE, Orwoll ES (1995) Body weight versus body fat distribution, adiposity, and frame size as predictors of bone density. J Clin Endocrinol Metab 80:1118-1123

13. Heiss CJ, Sanborn CF, Nichols DL, Bonnick SL, Alford BB (1995) Associations of body fat distribution, circulating sex hormones, and bone density in postmenopausal women. J Clin Endocrinol Metab 80:1591-1596

14. Tarquini B, Navari N, Perfetto F, Piluso A, Romano S, Tarquini R (1997) Evidence for bone mass and body fat distribution relationship in postmenopausal obese women. Arch Gerontol Geriatr 24:15-21

15. Douchi T, Yamamoto S, Oki T, Maruta K, Kuwahata R, Nagata Y (2000) Relationship between body fat distribution and bone mineral density in premenopausal Japanese women. Obstet Gynecol 95:722-725

16. Murillo-Uribe A, Carranza-Lira S, Martinez-Trejo N, SantosGonzalez J (2000) Influence of weight and body fat distribution on bone density in postmenopausal women. Int J Fertil Womens Med 45:225-231

17. Stewart KJ, Deregis JR, Turner KL, Bacher AC, Sung J, Hees PS, Tayback M, Ouyang P (2002) Fitness, fatness and activity as predictors of bone mineral density in older persons. J Intern Med 252:381-388 
18. Warming L, Ravn P, Christiansen C (2003) Visceral fat is more important than peripheral fat for endometrial thickness and bone mass in healthy postmenopausal women. Am J Obstet Gynecol 188:349-353

19. Blaauw R, Albertse EC, Hough S (1996) Body fat distribution as a risk factor for osteoporosis. S Afr Med J 86:1081-1084

20. Jankowska EA, Rogucka E, Medras M (2001) Are general obesity and visceral adiposity in men linked to reduced bone mineral content resulting from normal ageing? A populationbased study. Andrologia 33:384-389

21. Afghani A, Goran MI (2006) Racial differences in the association of subcutaneous and visceral fat on bone mineral content in prepubertal children. Calcif Tissue Int 79:383-388

22. Huang JS, Rietschel P, Hadigan CM, Rosenthal DI, Grinspoon S (2001) Increased abdominal visceral fat is associated with reduced bone density in HIV-infected men with lipodystrophy. AIDS 15:975-982

23. Vaessen N, Heutink P, Houwing-Duistermaat JJ, Snijders PJ, Rademaker T, Testers L, Batstra MR, Sandkuijl LA, van Duijn CM, Oostra BA (2002) A genome-wide search for linkage-disequilibrium with type 1 diabetes in a recent genetically isolated population from the Netherlands. Diabetes 51:856-859

24. Sayed-Tabatabaei FA, van Rijn MJ, Schut AF, Aulchenko YS, Croes EA, Zillikens MC, Pols HA, Witteman JC, Oostra BA, van Duijn CM (2005) Heritability of the function and structure of the arterial wall: findings of the Erasmus Rucphen Family (ERF) study. Stroke 36:2351-2356

25. Santos RL, Zillikens MC, Rivadeneira FR, Pols HA, Oostra BA, van Duijn CM, Aulchenko YS (2006) Heritability of fasting glucose levels in a young genetically isolated population. Diabetologia 49:667-672

26. Zillikens MC, Yazdanpanah M, Pardo LM, Rivadeneira F, Aulchenko YS, Oostra BA, Uitterlinden AG, Pols HA, van Duijn CM (2008) Sex-specific genetic effects influence variation in body composition. Diabetologia 51(12):2233-2241

27. Chen R, Yang Q, Chen F, Chen Y, Lin S (2005) Precision of total body composition using the Lunar Prodigy densitometer. Abstract ASBMR SU132

28. Snijder MB, Visser M, Dekker JM, Seidell JC, Fuerst T, Tylavsky F, Cauley J, Lang T, Nevitt M, Harris TB (2002) The prediction of visceral fat by dual-energy X-ray absorptiometry in the elderly: a comparison with computed tomography and anthropometry. Int J Obes Relat Metab Disord 26:984-993
29. Snijder MB, Dekker JM, Visser M, Bouter LM, Stehouwer CD, Yudkin JS, Heine RJ, Nijpels G, Seidell JC (2004) Trunk fat and leg fat have independent and opposite associations with fasting and postload glucose levels: the Hoorn study. Diabetes Care 27:372-377

30. Kamel EG, McNeill G, Han TS, Smith FW, Avenell A, Davidson L, Tothill P (1999) Measurement of abdominal fat by magnetic resonance imaging, dual-energy $\mathrm{X}$-ray absorptiometry and anthropometry in non-obese men and women. Int J Obes Relat Metab Disord 23:686-692

31. Kamel EG, McNeill G, Van Wijk MC (2000) Usefulness of anthropometry and DXA in predicting intra-abdominal fat in obese men and women. Obes Res 8:36-42

32. Clasey JL, Bouchard C, Teates CD, Riblett JE, Thorner MO, Hartman ML, Weltman A (1999) The use of anthropometric and dual-energy X-ray absorptiometry (DXA) measures to estimate total abdominal and abdominal visceral fat in men and women. Obes Res 7:256-264

33. Park YW, Heymsfield SB, Gallagher D (2002) Are dual-energy $\mathrm{X}$-ray absorptiometry regional estimates associated with visceral adipose tissue mass? Int J Obes Relat Metab Disord 26:978-983

34. Lee K, Lee S, Kim YJ, Kim YJ (2008) Waist circumference, dual-energy X-ray absortiometrically measured abdominal adiposity, and computed tomographically derived intra-abdominal fat area on detecting metabolic risk factors in obese women. Nutrition 24:625-631

35. Valentine RJ, Misic MM, Kessinger RB, Mojtahedi MC, Evans EM (2008) Location of body fat and body size impacts DXA soft tissue measures: a simulation study. Eur J Clin Nutr 62:553-559

36. Wang Q, Hassager C, Ravn P, Wang S, Christiansen C (1994) Total and regional body-composition changes in early postmenopausal women: age-related or menopause-related? Am J Clin Nutr 60:843-848

37. Morita Y, Iwamoto I, Mizuma N, Kuwahata T, Matsuo T, Yoshinaga M, Douchi T (2006) Precedence of the shift of body-fat distribution over the change in body composition after menopause. J Obstet Gynaecol Res 32:513-516

38. Bolotin HH (2007) DXA in vivo BMD methodology: an erroneous and misleading research and clinical gauge of bone mineral status, bone fragility, and bone remodelling. Bone 41:138-154 